\title{
New Brunswick overhauls trauma services
}

Published at www.cmaj.ca on Mar. 11

$\mathrm{M}$ ajor urban hospitals in New Brunswick will be precluded from denying trauma treatment to patients being transferred from rural and remote areas under a new provincial trauma system.

"It is essential that a 'no refusal' policy be implemented for all receiving centres in order to ensure that patients are transferred from sending to receiving hospitals with the maximum efficiency, in order to reduce potential morbidity," concluded the final report of a committee struck to develop a blueprint for provincial trauma services. Efforts to reform New Brunswick trauma care were launched in the wake of a highly publicized incident in which a rural resident waited 18 hours before entering the province's main trauma centre following an automobile accident (see sidebar).

Containing 112 recommendations, the New Brunswick Trauma System Final Report is the product of almost 20 months of work by some 100 health care workers (www.gnb.ca/0051/pdf /6832-e.pdf). Its goal: to create a coordinated trauma network that can treat patients injured anywhere in the province without unnecessary delay particularly when it comes to New Brunswick's annual load of roughly 250 major traumas.

The no-refusal policy is viewed as key to ensuring that patients do not become victims of bureaucratic wrangling between hospitals.

To achieve that, the report prescribes that "all Level 1,2 and 3 facilities must have a Trauma Team Leader (TTL) on call 24 hours per day and the Trauma Control Physician (TCP) or TTL readily available at all times. For Level 1 facilities, the TCP should also be the TTL. The TCP should not have any other professional commitments while on call and would not be 'hands on' in trauma cases. TTLs in Level 2 and 3 facilities should have a backup person to cover as TTL if they are not

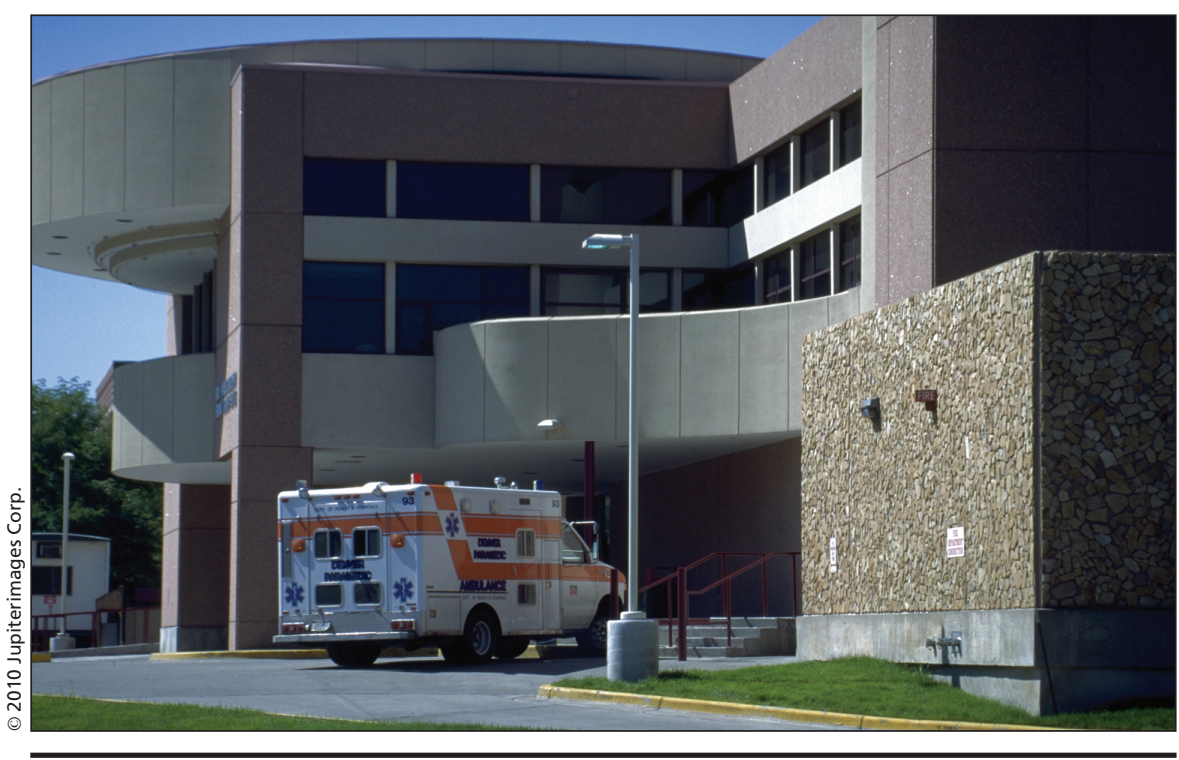

Rural physicians often face "tacit resistance" when trying to transfer a trauma patient to one of the province's larger hospitals, says Dr. Dennis Furlong, chairman of the New Brunswick Trauma System Advisory Committee.

readily available. Additionally, the province should implement a no-refusal policy within the province and establish formal agreements with other provinces such as Quebec and Nova Scotia."

Dr. Dennis Furlong, chairman of the New Brunswick Trauma System Advisory Committee, which crafted the report, recalls the "tacit resistance" he often faced when trying, as a rural physician, to transfer a trauma patient to one of the province's larger hospitals.

"I've been there many, many times as an emergency room physician in a rural area - pleading and almost begging for people to take your case," says Furlong, a long-time family physician in the province's north and a former Conservative health minister.

But come this spring, those calls will all flow through a toll-free trauma line meant to ensure that emergency room doctors have $24 / 7$ access to trauma specialists.

"The doctor with the injured patient now has to make one call, hang up the phone and get on with taking care of the patient," Furlong says. "Everything else is automatic."
With the blueprint complete, the task of actually building the New Brunswick trauma system falls to Dr. Marcel Martin, a trauma surgeon from Sherbrooke, Quebec.

The first step for Martin, the trauma program's medical director, is to eliminate "bad habits" and a lack of communication between hospitals. "There were fantastic (transfer) delays due to a lack of communication," he says. "We are addressing that as we speak."

For Martin, the goal is to establish an "inclusive system" - one that properly serves both rural and urban areas. That's not necessarily an easy task in a province with a population of roughly 750000 , where the bulk of health services are divided among three small cities in the south.

But Martin hopes the addition of video cameras to provincial emergency rooms will help doctors better coordinate and consult on trauma cases. And trauma simulations, using embalmed cadavers, will help physicians - particularly in rural areas — maintain their trauma skills. 
"Otherwise they're terrified of traumas and they make mistakes," he says.

Still, Martin stresses that a trauma network cannot be overhauled immediately. He adds that it will take many years to make all the necessary changes and improvements needed in New Brunswick. "It's going to take a while," he says. "The maturation is a long process." - Quentin Casey, Halifax, NS

DOI:10.1503/cmaj.109-3207
First of a series on trauma services.

Part 2: National trauma divide must be narrowed. (CMAJ 2010. DOI:10.1503/cmaj.109-3208)

\section{Trauma tale}

On the evening of Nov. 21, 2005, Donald Thomas left his home in Tracadie-Sheila, on the Acadian Peninsula in the extreme northeast of the province of New Brunswick, and headed down the road to deliver some fruit to his wife at the nearby Lamèque Hospital.

He never arrived at his destination. Instead, the events of that night forever altered his life and launched an overhaul of trauma care in New Brunswick.

While driving, Thomas was hit head-on by a pick-up truck. The impact left him with a slew of serious injuries, including multiple broken ribs, a bruised heart, a broken neck and a closed head injury. As well, his hips were broken and his femurs shattered.

It took an hour for Thomas, then 67 years old, to be cut from his vehicle with a jaws of life. "I was crushed inside the car," he recalls. "When they took me out, I was essentially dead."

Thomas's injuries clearly required treatment not available in the province's rural north. But his path to proper care was initially blocked because of resistance by larger hospitals to take him.

The lack of a coordinated trauma system caused Thomas to suffer for 18 hours before he arrived at the Saint John Regional Hospital — the province's main trauma centre. Finally there, he endured hours of surgery and rehabilitation that allowed him to walk again.

"It was like a beehive around the operating table," he recalls. "I don't remember a whole lot. I could see the nurses working on me. But it's as though I was looking through a fog."

Following the accident, it was hard to determine which was ravaged more: Thomas' body or the reputation of New Brunswick's health care system.

Shortly after, outrage from Thomas's family prompted the provincial government to launch a review of the ordeal. That initial study was but one of many conducted in the years following the accident — all aimed at evaluating and improving New Brunswick's ability to treat trauma patients. 